\title{
"It Feels Like I am Talking into a Void": Understanding Interaction Gaps in Synchronous Online Classrooms
}

\author{
Matin Yarmand \\ Design Lab, UC San Diego \\ La Jolla, CA \\ myarmand@ucsd.edu \\ Scott Klemmer \\ Design Lab, UC San Diego \\ La Jolla, CA \\ srk@ucsd.edu
}

\author{
Jaemarie Solyst \\ HCII, Carnegie Mellon University \\ Pittsburgh, PA \\ jsolyst@andrew.cmu.edu \\ Nadir Weibel \\ Design Lab, UC San Diego \\ La Jolla, CA \\ weibel@ucsd.edu
}

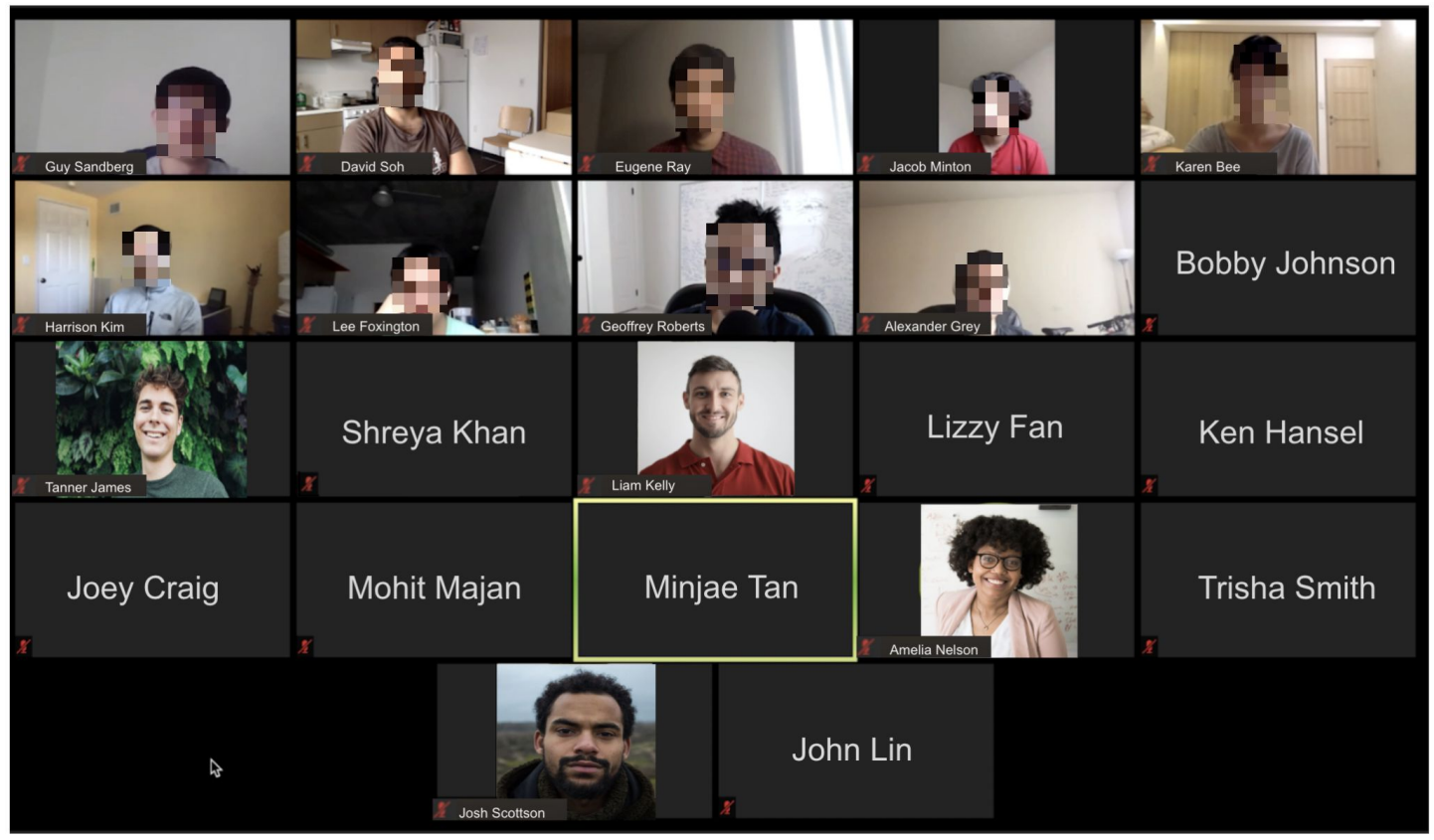

Figure 1: A pseudonymous snapshot of a 50-minute lecture with blurred, real faces for the video feeds. 13 out of 21 students are not sharing their videos, and everybody is muted except the one person who is speaking (outlined by a yellow border).

\begin{abstract}
This paper investigates in-class interactions in synchronous online classrooms when the choice of modality is discretionary, such that students choose when and if they turn on their cameras and microphones. Instructor interviews $(\mathrm{N}=7)$ revealed that most students preferred not to share videos and verbally participate. This hindered instructors' ability to read their classrooms and make deeper connections with students. Survey results $(\mathrm{N}=102)$
\end{abstract}

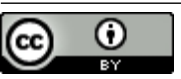

This work is licensed under a Creative Commons Attribution International 4.0 License.

CHI '21, May 8-13, 2021, Yokohama, Japan

(C) 2021 Copyright held by the owner/author(s)

ACM ISBN 978-1-4503-8096-6/21/05.

https://doi.org/10.1145/3411764.3445240 suggested that students felt a lacking sense of community in online vs. in-person lectures. Some students felt uncomfortable broadcasting their appearances to everyone in the class, and some were unaware of the benefits for instructors. Most students favored using the text chat to participate. Considering the needs of both instructors and students, we propose recommendations to mitigate the loss of classroom interactions by collecting and presenting less invasive social cues in an aggregated format, and incorporating opportunities for informal exchanges and individual control to spark peer bonding.

\section{CCS CONCEPTS}

- Applied computing $\rightarrow$ Distance learning; Distance learning; • Human-centered computing $\rightarrow$ Empirical studies in $\mathrm{HCI}$; Empirical studies in HCI. 


\section{KEYWORDS}

Online Education, Synchronous Online Learning, In-class Interactions, Learners, Instructors

\section{ACM Reference Format:}

Matin Yarmand, Jaemarie Solyst, Scott Klemmer, and Nadir Weibel. 2021. "It Feels Like I am Talking into a Void": Understanding Interaction Gaps in Synchronous Online Classrooms. In CHI Conference on Human Factors in Computing Systems (CHI '21), May 8-13, 2021, Yokohama, Japan. ACM, New York, NY, USA, 9 pages. https://doi.org/10.1145/3411764.3445240

\section{INTRODUCTION}

The instructor of a 22-person graduate class recently taught his first synchronous online classroom. During the discussion-based lecture, only a few of his students decided to share their videos, and they stayed muted for the entire time except when it was their turn to take part in the conversation. This occurred during our observations of a live virtual lecture at a large research university, shown in Fig 1. Research shows that when students cannot see one another in a learning environment, they feel isolated [47] and dissatisfied [27]. However, most students still decided to not share their videos. Experienced instructors, who are usually able to adjust teaching according to students' emotional and cognitive signals [7, 69], fail to read their classrooms and understand students' changing needs in real-time, since their students appear as only a grid of black rectangles.

When teaching university classes online, many instructors opt in for synchronous approaches due to the benefit of real-time interaction. Enhanced classroom interaction is shown to improve learner satisfaction [12, 57], class retention [52], and learning gains [8]. These interactions are facilitated via communication modalities such as text, audio, and video; text chat is shown to boost students' grammatical consciousness, while video enhances social presence and learning performance [70]. Besides, a learner's cultural background may affect talkativeness in video-enabled chat vs. text-only communication [64], and online behaviour can change depending on the degrees of anonymity and synchronicity of the virtual exchanges [24].

Prior work on systems for synchronous online classrooms assumed interaction modalities, specifically students' use of video $[7,8,66]$. This paper presents the first results on students' and instructors' behaviors when the choice of modality is discretionary, meaning students choose to share their video and audio during lectures. We highlight why most students elect not to share their videos and how this has detrimental consequences for instructors to read their classrooms. We also show how online classrooms hinder informal student-instructor and student-student interactions. Finally, we discuss approaches for remedying these losses by encouraging the use of chat, incorporating flexibility into the content and distribution of video feeds, presenting engagement and confusion signals in an aggregated format, and creating opportunities for informal connections while enabling individual control over the interactions. This work contributes to the literature of online education post the COVID-19 outbreak (e.g., Chen et al.'s work [9] on K-12 and college students in China) which prompted a sudden shift from in-person teaching to live virtual classrooms.

\section{RELATED WORK}

We review strategies of in-class interactions according to Moore's [40] taxonomy and how the findings of this study relate to each type of interaction.

\subsection{Student-instructor Interaction: Class Participation}

Class participation is broadly defined as in-class student engagement that results in an enhanced personal and professional development and satisfied classroom experience [25, 29, 32]. Active in-class participation increases students' motivation [34], improves critical thinking skills [14, 23], positively shapes character [38], and yields higher learning outcomes [17, 21, 67]. Despite these benefits, studies show that student participation is highly polarized: Howard and Henney [30] found that $90 \%$ of class participation was linked to a handful of students, while half of the students did not participate at all.

To encourage student participation, instructors typically incorporate strategies such as instructor-initiated questions that aim to prompt responses from students. However, these strategies tend to be limiting, since only one person responds at a time [46], and interactions can be dominated by certain students [20]. While cold-calling (i.e., calling on students without warning) can diversify students who respond, it can be disadvantageous for more introverted individuals and students from other backgrounds [43]. Lastly, personal voting systems, such as clickers, have been shown to improve cooperation [49] and perception of review questions [54], but they cannot be effectively used for in-depth discussions. In this study, we explore instructors' methods of promoting participation in synchronous online lectures, given the lack of students' video feeds.

\subsection{Student-content Interaction: Lecture Content}

Moore [40] defines student-content interaction as the process of intellectually interacting with the learning content to prompt changes in the learners' understanding, perspective, and cognitive structures. In-class student interactions with the content can include the time spent on PowerPoint slides and other educational web pages during class time [56]. This type of interaction is fundamental for education [62] and critical for learning [60]. However, compared to the other types of interaction, studentcontent has received the least attention in the literature due to its broad nature that can vary widely depending on course structure [71]. In this paper, we investigate students' interaction with the lecture content, and propose recommendations for how instructors can benefit from existing social cues (i.e. engagement and confusion) to manage their online classrooms.

\subsection{Student-student Interaction: Sense of Community}

Sense of community is broadly defined as "a feeling that members have of belonging, a feeling that members matter to one another, and a shared faith that members' needs will be met through their commitment to be together" [39]. Having a sense of 
community in the classroom yields personal and academic benefits, including increased classroom participation and learning [22], better emotional well-being and stress management $[48,55]$, as well as better rates of persistence and attrition [15]. However, in online classes, there are not as many opportunities to interact and connect with peers, which increases feelings of isolation for some students [37]. Students in online settings may also struggle more with creating and maintaining friendships as they take part in their studies [13].

In-class student activities can aid community building. Certain peer-to-peer interactions that contribute most to a sense of community include self-introductions, disclosing personal experiences, discussions with the entire class, and exchanging resources (e.g., notes or techniques) [53, 61]. This paper reveals new insights about students' challenges to make connections and build community in online learning environments. We also offer design recommendations to enhance informal interactions.

\section{PHASE I: INTERVIEWS WITH INSTRUCTORS}

To understand instructors' experience of conducting online lectures and how it compares to in-person teaching, we interviewed 7 instructors.

\subsection{Methods}

Participants. We invited 12 instructors from University of California San Diego to participate in our interview study according to convenience sampling. All invitees taught at least one online class at the time of the interviews. 7 instructors ( 1 female, 6 male) participated who represented 5 departments and had 1 to 22 years of teaching experience. Two instructors (i.e. I2 and I3) had created MOOC lectures, but none had previously taught a synchronous online class. The instructors taught 3 graduate and 4 undergraduate online classes on the teleconferencing system Zoom, ranging from 15 to 189 students. 5 classes contained separate lab and discussion sections which were managed by teaching assistants. Table 1 describes the instructors and their online courses.

Interviews. We conducted semi-structured interviews in the middle of the Spring quarter. These interviews took place over Zoom and lasted 30 to 45 minutes. Instructors described their course structure, in-class interaction with students, challenges of managing lectures, and how their experience compared to prior in-person classrooms. We recorded all sessions and anonymized the transcripts for analysis.

Analysis. The first author open coded the transcripts and combined the initial codes into preliminary topics via inductive thematic analysis [11]. All authors then iteratively discussed and revised the emerging ideas into four themes as described below.

\subsection{Results}

Reading Engagement and Confusion was Challenging 6 instructors (out of 7) expressed limited understanding of students in their classes, because they did not share their videos and audios during the lecture. I5, the instructor of a 15-person graduate-level lecture, compared his experience to a monologue:
"When I'm presenting the lecture content, it feels like I'm talking into a void. [...] I think the particular choice of void was something I felt the first day. And I kept that feeling. I'm literally in my own bedroom talking into a black wall and it's complete silence. Everyone's muted. And I have my headphones on, and it's kind of echoey and it feels like I am talking to myself. It kind of became a monologue." (I5)

Comparing their experience to prior in-person classrooms, instructors identified specific types of cues that they needed to understand their students: engagement and confusion. For instance, I7 struggled with the lack of awareness from his students' engagement:

\begin{abstract}
"One of my biggest challenges [in online teaching] is mostly engagement. How do you tell whether students are engaged? Somehow if I could know how many students are tuned out, how many students are not looking at the Zoom, but looking at some other web pages that are not related, that is just useful for me."
\end{abstract}

In addition, I1, who was well-experienced in teaching large inperson classrooms over the years, struggled to detect student confusion in an online environment: "Now you can't read at all if people are understanding stuff. You have no sense if people are getting it or not getting it".

\begin{tabular}{|c|c|c|c|c|c|c|c|}
\hline Instructor & $\begin{array}{c}\text { Years of } \\
\text { Teaching }\end{array}$ & Department & $\begin{array}{c}\text { Course } \\
\text { Mode }\end{array}$ & Course Level & $\begin{array}{c}\text { Course } \\
\text { Size }\end{array}$ & $\begin{array}{c}\text { Duration } \\
\text { (mins) }\end{array}$ & $\begin{array}{c}\text { Sessions } \\
\text { per Week }\end{array}$ \\
\hline I1 & 22 & Biology & Lecture & Undergraduate & 189 & 80 & 1 \\
\hline I2 & 15 & Management & Seminar & Graduate & 25 & 180 & 1 \\
\hline I3 & 16 & Data Science & Lecture & Graduate & 31 & 80 & 2 \\
\hline I4 & 6 & Biology & Lecture & Undergraduate & 185 & 80 & 1 \\
\hline I5 & 2 & Computer Engineering & Lecture & Graduate & 15 & 50 & 3 \\
\hline I6 & 9 & Cognitive Science & Lecture & Undergraduate & 89 & 80 & 2 \\
\hline I7 & 1 & Cognitive Science & Lecture & Undergraduate & 92 & 80 & 2 \\
\hline
\end{tabular}

Table 1: Background details on the 7 instructors and their remote courses at the time of the interviews. I1 and I4, as well as I6 and I7, taught two sections of the same course. 


\section{Aggregation and Simplification Assist Reading the Classroom}

Instructors talked about strategies that they used in co-located classrooms to better digest the social cues from students. One technique was selectively paying more attention to a subgroup of students who engaged more with the content. I6 explained his strategy for reading a classroom of 89 students when it was conducted in-person:

"I think generally in class, you end up picking on some students who are more verbal, who are more engaged, who are paying attention; and just by nature, you end up honing in on them." (I6)

Reflecting on online classrooms, some instructors proposed simplifying students' videos to assist teaching: I7 favored an aggregated signal that would help him read his large classroom.

"I am looking for some ways of aggregation, some ways of simplifying the information, because I just want to know whether the students are paying attention. That's all I need to know. I don't really need to know whether they are wearing glasses, whether they have long hair, short hair, girl, or boy. I don't really care about that." (I7)

\section{Lack of Student Participation Led to Alternative Methods of Engagement}

6 out of 7 instructors talked about the lack of students' verbal participation in class. Comparing their online classes to previous in-person offerings, some instructors said that "there are people who don't want to vocalize their questions at all" (I5), and "students are very, very reluctant to speak up" (I1). I5 also mentioned a noticeable silence once he asked a question from students: "When I ask a question, there is a gigantic lag before someone says something". Some instructors believed that the nature of remote attendance led to this behaviour:

"I think that the screen has become a crutch for students not to engage in class. I bet you a good percentage of them when they listen in on lectures, they're laying in bed." (I6)

To alleviate the lack of verbal participation, instructors relied on other techniques to engage their students. Encouraging students to participate in the chat section was a common strategy; for instance, I1 mentioned that she "tried to get students to respond in the chat" instead of having the students to speak out loud. Some instructors allocated time in between when they asked a question and when they expected students to respond:

"I usually put questions to the students just to get them thinking about it for a while. I ask them to write something in chat, and then I would have to look at that and verbalize what had been typed." (I6)

I 2 - who taught an online class with all 25 students sharing their videos - employed a similar technique for cold-calling in online lectures:

"I am unafraid to cold call. Online, I've adopted more of a warm call where I'll say, hey fohn, in a couple of minutes we're going to come back, and I'd like you to discuss this topic with us a little bit." (I2)
Similar to clicker questions in physical classrooms, I1 used an integrated polling feature and emphasized the benefits of review questions to understand her students:

"To engage students is to give them little quizzes. They like quizzes, and they like to get the answer right. So that doesn't mean they're going to show their face, but it does tell me that at least behind that black screen, there's something going on."

While instructors reported improvements in student engagement after using these strategies, overall they found the online setting more challenging to promote student participation.

Online Lectures Posed Barriers for Connecting with Students Some instructors struggled to socially interact with students in a synchronous online classroom: they struggled to engage in informal conversations and make deeper connections with students:

"I think one of the important things about teaching is just feeling a connection to the students, and the students feel like you care. You can joke around with them in class, and you can chat with them before, and you can chat with them afterward, and it's just not the same. But I think that's actually an important part of teaching, which is just making this human connection." (I1)

\section{PHASE II: STUDENT SURVEY RESPONSES}

To understand students' perspectives on attending online lectures, we developed and distributed a survey with Likert-scale and openended questions.

\subsection{Methods}

Participants. We distributed the survey to 1,064 students in 13 online classes (4 graduate and 9 undergraduate) during the Spring and Summer quarters. 102 students (9.6\%) filled out the survey with varying degrees of completion; 81 fully completed the survey, while the responses of the other 21 students were partially recorded. The demographics of the 102 participants is as follows: gender (56 female, 44 male, 2 non-binary), academic level (95 undergraduate, 7 graduate), nationality (15 types in total with American $(\mathrm{N}=52)$ and Chinese $(\mathrm{N}=21)$ as the majority).

Survey. The students survey asked for demographics and investigated three broad topics: (i) lecture participation, (ii) remote learning environment, and (iii) communication channels. It contained a mix of Likert-scale and open-ended questions about the specific class that the students were taking. Survey prompts were inspired by the interviews with instructors and their speculations about students' circumstances; for instance, we used I6's 'I bet you a good percentage of them when they listen in on lectures, they are laying in bed" to present the following two prompts: During lecture, I am positioned right in front of a webcam, and I use a productive workspace at home. We provided additional open-ended response boxes for further elaboration on the Likert-scale prompts.

Analysis. We analyzed the open-ended questions using a mix of inductive (i.e., bottom-up) and theoretical (i.e., top-down) thematic analyses [11]. The inductive approach followed a similar opencoding process as in phase I. We used instructors' interviews 
to inform our analysis in a top-down manner; for instance, we used themes such as "chat" and "participation" to collect students' responses in different sections of the survey.

\subsection{Results}

Figure 2 displays the Likert-scale prompts and the distribution of responses. While these responses cover broad topics (e.g., students' remote living circumstances, breakout room participation, and group projects), this work highlights in-class interactions. The complete survey results are included in the supplemental material for future exploration.

\section{Students Were Reluctant to Turn on Their Cameras}

The survey responses revealed that students were reluctant to share their video feeds, similar to what 6 of the instructors mentioned in phase I. $80 \%$ of students always turned their cameras off, and $84 \%$ kept their microphones muted. Contrary to what one of the instructors hypothesized, $71 \%$ of students were positioned in front of a webcam during lectures. The survey also contained an openended question about students' reasons for not sharing videos, which we discuss in this section.

Out of 52 written responses, 23 students (44\%) expressed discomfort with displaying their appearances. Some students reported reluctance to look presentable in a remote environment; for instance, one student said: "I don't want to show my face when I'm in my home clothes, haven't showered, etc." In addition, some students - who performed other activities during lecture expressed discomfort broadcasting these activities; two students mentioned: "when I haven't eaten, I'll eat while attending the lecture and don't want people to see me," and "it feels weird to have a camera on me while I take notes". Interestingly, eating and taking notes are common activities in physical classrooms.

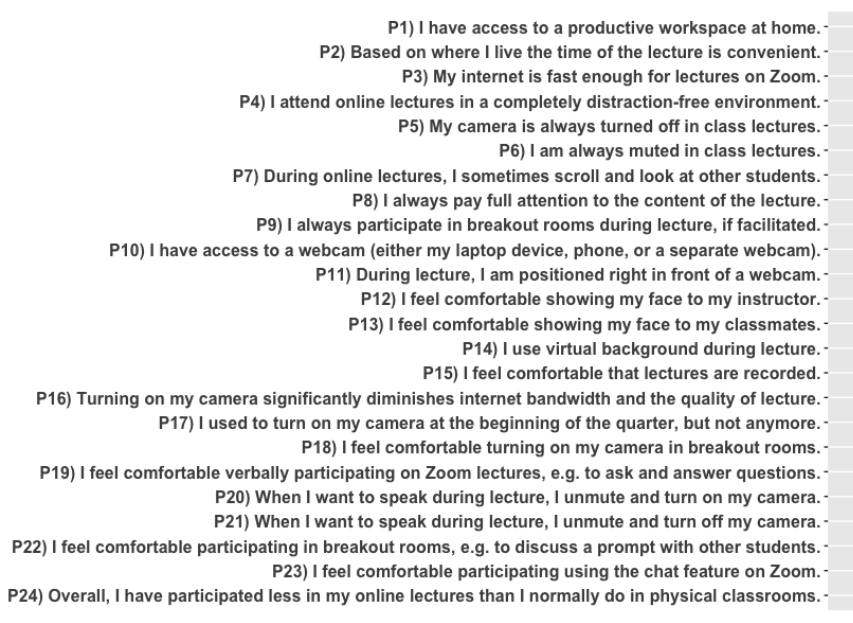

Figure 2: The distribution of students' responses for the Likert-scale prompts. Students showed reluctance to turn on their cameras and unmute their microphones during lectures. Interestingly, most indicated that they had access to working webcams but chose not to use them.
14 students $(27 \%)$ believed that sharing videos served no purpose and thus avoided doing so: "there is no need for my camera to be on". Some students were unaware of benefits of their video feeds for instructors, as described in phase I. Also, 12 students $(23 \%)$ attributed their decision to the consensus among their peers: "nobody else has their camera on, and I feel awkward turning mine on" and "that's what all other students do".

Other less common reasons consisted of having limited access to a webcam and preventing distraction for the class: "the camera on may distract other students if I am fidgeting or moving around, so it's just better to keep it off".

\section{Chat Fostered Student Participation}

Students felt less social anxiety asking questions in the chat instead of verbalizing to the entire class. This is evident from the Likert-scale responses, as $80 \%$ responded positively to use the chat compared to a smaller $45 \%$ who felt comfortable to speak out loud. They brought up concerns regarding speaking in a large class and asking seemingly unintelligent questions:

\begin{abstract}
"It's a bit nerve racking to ask questions in a big 200 person lecture when you feel that everyone is staring at you, and perhaps the professor may not even answer the question properly, but you don't want to ask for clarification."

"I am not forced to really show who I am. Because of this, I feel better asking questions using the chat, since no one is going to know who I am. In person, everyone looks at you, and if you ask a dumb question, they will always know and remember my face."
\end{abstract}

Students also felt uncomfortable interrupting the flow of the lecture to ask questions: "I'm more comfortable asking questions in chat, since I feel less like I'm interrupting the lecture”.

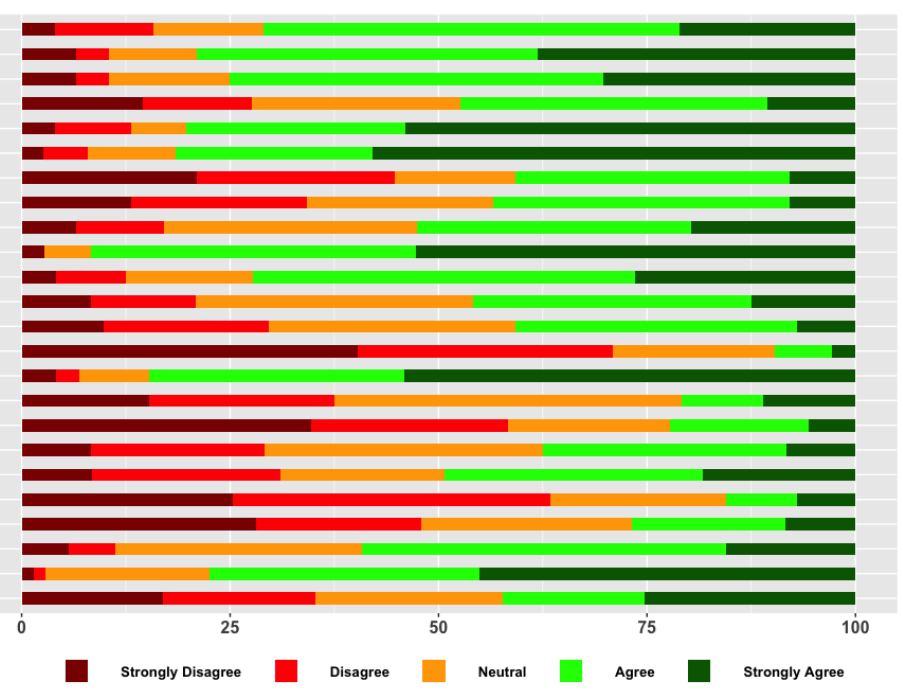

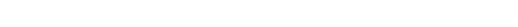


Other students were concerned about the technological difficulties to verbally ask questions, and they perceived the chat feature as more reliable:

"I don't speak, because written questions sent in as chat messages are guaranteed to get across clearly and accurately, whereas a microphone or speaker on the sender or receiver's side could malfunction."

As mentioned above, using the chat alleviated social anxiety and the interrupting nature of asking questions verbally. Students reported that lowering these barriers encouraged asking more and deeper questions:

"I have participated way more in online lectures. It is easier now to ask a question and write in the chat than raise my hand in a huge lecture hall."

"I ask more in depth questions online, because I feel as though the chat feature is not as disruptive."

Besides, some students indicated that chat facilitated informal interaction with their peers: "I find the chat room also a great place to build community with other students, because usually we would not interact with each other as much". Overall, the chat feature addressed some of the gaps in student participation, mainly fostered asking questions and interacting with other students.

\section{Students Struggled to Connect with Peers and Instructors}

The survey showed students' challenges to socially interact with instructors and their classmates. Students struggled to find opportunities to connect with their instructors, such as the lack of post-lecture time. As indicated by the survey responses, after class is a popular time to connect with the instructor for questions about or beyond the course and have more informal exchanges.

"I think interactions with the professor are basically nonexistent. I hear my professor did social work or something like that, and under normal circumstances, I would come to him after lecture and make some short conversation about that. [...] I want to know how my major could connect to helping people, but I guess I'll save that conversation for some other day".

"When I have questions about the assignment, I can ask instructors right after the class. But for online lectures, I cannot do so."

Some students pointed out that in-class social engagements with instructors were different, commenting that "professors don't make as many jokes, because they don't get any feedback, so it's incredibly dry". Online lectures also did not effectively facilitate peer-to-peer interactions or serve as a starting point for deeper bonding (i.e., friendship). One student commented, "it's not easy to meet people and make friends like it was with in-person lectures". This point was echoed by another student:

"I miss the interaction with others. That's half the reason you take classes in the first place [...] I met some of my closest friends in my major and elective classes. This is a lost opportunity to get to know some cool people".

Online Lectures Lacked Sense of Community

Many students felt the lack of community in online classrooms and mourned the higher social connection afforded in co-located lectures: "it feels weird to never actually see or talk to classmates and professors in person. It feels impersonal". Another student elaborated on a similar sentiment:

"I miss getting feedback from other people in the class, because usually I look around to see if they're as confused as I am, so there's no camaraderie there. If other students have problems with the class, normally they say so in class. Now it's all through email, so I can't tell if people are having the same issues as I am, so it's incredibly isolating”.

\section{DISCUSSION: NEEDS AND RECOMMENDATIONS}

This section articulates the needs that emerged from our analyses and presents broad recommendations - based on observational research [18] - for instructors and online lecture technologies.

\subsection{Flexible and Weighted Distribution of Video Feeds}

The majority of students reported reluctance to share their videos during lecture: some students were uncomfortable to broadcast their appearances to the entire class, and some were unaware of the benefits for their instructors.

Incorporating flexibility in what and how students share visual cues can promote engagement. Due to the remote nature of attendance in online lectures, students might not be expected to offer the same level of visual data; for instance, students who share bedrooms with other siblings are less likely to turn on their videos compared to ones who live by themselves. Less invasive forms of social cues (e.g., facial expressions and nods) might be more appropriate for students who do not wish to fully broadcast their faces and surroundings. The detection and extraction of facial landmarks have been widely used in online learning environments (e.g., Intelligent Tutoring Systems) to accurately characterize states that contribute to students' learning, such as confusion and engagement $[2-4,26,51]$. While we did not collect students' thoughts on sharing facial expressions, Wang et al. [65] finds that students are receptive to offering their affect data to help instructors improve teaching.

Another solution can be to enable students to control how they send their visual feeds and receive others'. Our results revealed that some students felt uncomfortable to share their videos, because all their classmates were able to see them and might even find their video feeds distracting. Classrooms are traditionally designed to follow a behavioristic model [28] and put the instructor as the focal point of learning [68]. However, video conferencing tools assign the same level of attention to every attendee; this model represents a meeting scenario in which all participants are given the same priority with the spotlight set to the person speaking. Future lecture delivery systems can consider a flexible model that enables students to adjust how they send and receive video feeds: for instance, students can assign most attention on the instructor's video, less attention on friends, and receive no feeds from others. 


\subsection{Aggregated and Simplified Presentation of Real-time Social Cues}

Instructors highlighted the importance of in-class social signals for tailoring lectures according to students' needs. To adjust teaching on the fly, instructors can benefit from receiving specific visual cues that they need (i.e., engagement and confusion signals) in a digestible manner. Our interview findings revealed that instructors (specifically, I6 and I7) seek aggregated information that they can effectively incorporate into their teaching. This is especially important in large classes where it might be more difficult to monitor all students. Chen's [7] remote video system clusters classroom signals (i.e., speech activity and body motion) in a timeline at the bottom of the instructor's view. Similar visualization strategies can be used for real-time engagement and confusion signals. Moreover, instructors selectively pay more attention to a subgroup of students who are more engaged with the lecture content. Particularly in large in-person classrooms, this strategy helps instructors filter through all available social cues and extract ones that are more beneficial to their teaching. Online lecture platforms can consider the engagement levels of students to order the video feeds that an instructor can view.

\subsection{Chat to Satisfy and Exceed Interaction Gaps}

The text chat in online lectures have created opportunities to not only match but also improve overall student participation in physical classrooms. Many of the students noted that they felt more comfortable asking questions in the chat instead of having to speak out loud. Participation avoidance due to the feeling of intimidation from others or self-inadequacy have been pointed out in prior literature [31,36, 67], dubbed with the term "classroom apprehension" [41]. Our results show that compared to verbal participation, chat fosters less social anxiety, and hence, lowers classroom apprehension. This is consistent with prior work that suggests students who self-rate higher in shyness prefer asynchronous chat to in-person interaction [1]. Increasing participation among shy students can lead to a less polarized and biased classroom atmosphere in which instructors might otherwise favor the more extroverted students [6]. Additionally, research shows that international students - who primarily speak a different language than the language of the class - lack confidence to participate [35, 58]. For non-native students, including 50 responses in our survey (49\%), it might be easier to type their questions rather than ask verbally.

We recommend instructors to take advantage of this feature as a complement to other modalities of engagement. In addition, students can be invited to use the chat beyond solely asking questions from instructors. It has been shown that social and collaborative interaction in web-based instruction lead to higher learning and satisfaction outcomes [33], so students can be encouraged to reflect on other students' thoughts and collaboratively discuss the lecture content.

\subsection{Creating Opportunities for Social Interaction and Community-Building}

Start of peer relationships is often sparked in the classroom, and friendships can develop outside of the lecture time. However, without the classroom being a place for initiating informal social connections, students are less likely to develop stronger ties outside of the lecture. Friendship and meaningful networking are major benefits of university life, as they relate to belonging and retention [5], as well as increased learning gains [10]. Social interactions are especially important when students are reluctant to share videos during class, exacerbating the feeling of isolation [47]. For the scope of this paper, we consider recommendations that are related directly to immediately before, after, and during online lecture sessions, although student bonding can be supported beyond the class time.

In order to spark peer-to-peer connections, we encourage more opportunities for informal interactions. First, for bonding opportunities directly before and after lecture, we recommend adding "hall time" [45] to both the start and end of online class time. This allows students to enter the virtual lecture space earlier and leave later in order to interact with their peers and instructor. This type of lightweight addition can help students to connect with one another, build a stronger sense of community, and potentially initiate future friendships. Even informal interactions with "weaktie" acquaintances (i.e., semi-familiar peers in the same class) yield benefits to well-being and community-building [50]. Students' informal exchanges with peers and instructors may also result in promoting networking and gaining helpful academic information (e.g., tips about their major). Interaction and peer mentorship beyond synchronous educational video streams have been shown to cultivate further engagement and online community [19].

Second, for bonding opportunities during class time, we encourage incorporating low-investment social opportunities in students' group discussions. For example, since students can connect through sharing personal experiences [53], students may be prompted to self-disclose something more personal (e.g., their favorite movie) at the start of each small group discussion. Peer discussions can reduce social anxiety and promote confidence [59], and self-disclosure specifically helps build and strengthen friendships [63].

Creating personal spaces for informal interactions can also promote community-building. "Individual control" [45] is another characteristic of co-located interactions that is missing in synchronous online classrooms. Given the time before or after lecture, students might still feel uncomfortable discussing informal topics in the presence of all other students; research shows that students who are inactive in large gatherings become more engaged in smaller groups [42]. While online lectures facilitate direct chats, they might not feel as personal as richer forms of communications (e.g., audio) [16, 44]. Enabling students to freely create rich interactions in smaller settings can be considered in future lecture delivery systems.

\section{LIMITATIONS AND FUTURE WORK}

This work provides empirical evidence from instructors and students about interaction gaps at a large research university. While we think that our results accurately represent this specific educational setting, other lecture types might have needs that differ from the ones identified in our study; for instance, instructors of smaller college classes might desire more understanding from their students beyond aggregated confusion and engagement 
signals. Future studies can explore alternative online learning environments.

While we limited the scope of this study to interactions during lecture time, other synchronous (e.g., office hour meetings) and asynchronous (e.g., email) interactions occur in an online learning environment. Exploration of these interactions can yield more insight on needs and offer opportunities to enhance engagement. Emotional states of students in each type of interaction can also be studied more comprehensively.

Interviews revealed instructors' needs to read their classrooms in an easily comprehensible format. Future work can investigate the design of an instructor dashboard for presenting students' engagement and confusion. Collecting, aggregating, and presenting students' social cues non-disruptively and in real-time may be a promising study direction. Our recommendation of "hall time" also requires more exploration to discover effective implementations and assess potential impacts on student bonding.

Finally, while our survey results indicated a strong preference for the use of chat, we did not examine the types of messages that were exchanged between instructors and students. Future investigation of chat can reveal specific needs of in-class text interactions and inform the design of lecture delivery systems.

\section{CONCLUSION}

This paper presents empirical findings on synchronous online classrooms when students' choice of modality is discretionary. We find that students avoided sharing their videos which hindered instructors to read their classroom and students to socially interact. Students provided reasons such as discomfort with displaying their appearances. They instead preferred using the chat to ask questions. Our results point to design recommendations such as incorporating video sharing flexibility for students and aggregating engagement and confusion signals for instructors. We also suggest including informal time immediately before and after lecture, low-cost opportunities for informal exchange during lecture, and accommodating individual control for rich interactions in small settings.

\section{ACKNOWLEDGMENTS}

We thank the instructors and students at UC San Diego who participated in the interview and survey studies.

\section{REFERENCES}

[1] Yun-Jo An and Theodore Frick. 2006. Student perceptions of asynchronous computer-mediated communication in face-to-face courses. Fournal of ComputerMediated Communication 11, 2 (2006), 485-499.

[2] Marian Stewart Bartlett, Gwen Littlewort, Ian Fasel, and Javier R Movellan. 2003 Real time face detection and facial expression recognition: development and applications to human computer interaction. In 2003 Conference on computer vision and pattern recognition workshop, Vol. 5. IEEE, 53-53.

[3] Nigel Bosch, Yuxuan Chen, and Sidney D'Mello. 2014. It's written on your face: detecting affective states from facial expressions while learning computer programming. In International Conference on Intelligent Tutoring Systems. Springer 39-44.

[4] Nigel Bosch, Sidney K D'mello, Jaclyn Ocumpaugh, Ryan S Baker, and Valerie Shute. 2016. Using video to automatically detect learner affect in computerenabled classrooms. ACM Transactions on Interactive Intelligent Systems (TiiS) 6 , 2 (2016), 1-26.

[5] Vanessa M Buote, S Mark Pancer, Michael W Pratt, Gerald Adams, Shelly BirnieLefcovitch, Janet Polivy, and Maxine Gallander Wintre. 2007. The importance of friends: Friendship and adjustment among 1st-year university students. Fournal of adolescent research 22, 6 (2007), 665-689.
[6] Susan Cain. 2013. Quiet: The power of introverts in a world that can't stop talking. Broadway Books.

[7] Milton Chen. 2003. Visualizing the pulse of a classroom. In Proceedings of the eleventh ACM international conference on Multimedia. 555-561.

[8] Nian-Shing Chen, Hsiu-Chia Ko, Kinshuk, and Taiyu Lin. 2005. A model for synchronous learning using the Internet. Innovations in Education and Teaching International 42, 2 (2005), 181-194.

[9] Xinyue Chen, Si Chen, Xu Wang, and Yun Huang. 2021. " I was afraid, but now I enjoy being a streamer!" Understanding the Challenges and Prospects of Using Live Streaming for Online Education. Proceedings of the ACM on Human-Computer Interaction 4, CSCW3 (2021), 1-32.

[10] Seunghoo Chung, Robert B Lount Jr, Hee Man Park, and Ernest S Park. 2018. Friends with performance benefits: A meta-analysis on the relationship between friendship and group performance. Personality and Social Psychology Bulletin 44, 1 (2018), 63-79.

[11] Victoria Clarke, Virginia Braun, and Nikki Hayfield. 2015. Thematic analysis. Qualitative psychology: A practical guide to research methods (2015), 222-248.

[12] Michele T Cole, Daniel J Shelley, and Louis B Swartz. 2014. Online instruction, e-learning, and student satisfaction: A three year study. The International Review of Research in Open and Distributed Learning 15, 6 (2014).

[13] Dianne Conrad. 2005. Building and Maintaining Community in Cohort-Based Online Learning. International fournal of e-Learning and Distance Education 20 (2005), 1-20.

[14] James A Crone. 1997. Using panel debates to increase student involvement in the introductory sociology class. Teaching Sociology 25, 3 (1997), 214-218.

[15] Bruce D Curry. 2001. Collaborative, connected, and experiential learning: Reflections of an online learner. (2001).

[16] Kristen Cuthrell, Elizabeth Fogarty, and Patricia Anderson. 2009. 'Is this thing on?'University Student Preferences Regarding Audio Feedback. In Society for Information Technology \& Teacher Education International Conference. Association for the Advancement of Computing in Education (AACE), 32-35.

[17] Luann M Daggett. 1997. Quantifying class participation. Nurse Educator 22, 2 (1997), 13-14.

[18] Paul Dourish. 2006. Implications for design. In Proceedings of the SIGCHI Conference on Human Factors in Computing Systems. 541-550.

[19] Travis Faas, Lynn Dombrowski, Alyson Young, and Andrew D Miller. 2018. Watch me code: Programming mentorship communities on twitch. tv. Proceedings of the ACM on Human-Computer Interaction 2, CSCW (2018), 1-18.

[20] Linda Marie Fritschner. 2000. Inside the undergraduate college classroom: Faculty and students differ on the meaning of student participation. The fournal of Higher Education 71, 3 (2000), 342-362.

[21] Darin L Garard, Lance Lippert, Stephen K Hunt, and Scott T Paynton. 1998. Alternatives to traditional instruction: Using games and simulations to increase student learning and motivation. Communication Research Reports 15, 1 (1998), 36-44.

[22] D Randy Garrison, Terry Anderson, and Walter Archer. 2010. The first decade of the community of inquiry framework: A retrospective. The Internet and Higher Education 13, 1-2 (2010), 5-9.

[23] Colleen Garside. 1996. Look who's talking: A comparison of lecture and group discussion teaching strategies in developing critical thinking skills. Communication Education 45, 3 (1996), 212-227.

[24] Amy L Gonzales and Jeffrey T Hancock. 2008. Identity shift in computer-mediated environments. Media Psychology 11, 2 (2008), 167-185.

[25] C Gopinath. 1999. Alternatives to instructor assessment of class participation. Journal of Education for Business 75, 1 (1999), 10-14.

[26] Joseph F Grafsgaard, Joseph B Wiggins, Kristy Elizabeth Boyer, Eric N Wiebe, and James C Lester. 2013. Automatically recognizing facial indicators of frustration: a learning-centric analysis. In 2013 Humaine Association Conference on Affective Computing and Intelligent Interaction. IEEE, 159-165.

[27] Charlotte N Gunawardena and Frank J Zittle. 1997. Social presence as a predictor of satisfaction within a computer-mediated conferencing environment. American Journal of Distance Education 11, 3 (1997), 8-26.

[28] Ali Guney and Selda Al. 2012. Effective learning environments in relation to different learning theories. Procedia-Social and Behavioral Sciences 46 (2012), 2334-2338.

[29] James E Heyman and John J Sailors. 2011. Peer assessment of class participation: applying peer nomination to overcome rating inflation. Assessment \& Evaluation in Higher Education 36, 5 (2011), 605-618.

[30] Jay R Howard and Amanda L Henney. 1998. Student participation and instructor gender in the mixed-age college classroom. The fournal of Higher Education 69, 4 (1998), 384-405.

[31] Cheryl A Hyde and Betty J Ruth. 2002. Multicultural content and class participation: do students self-censor? fournal of Social Work Education 38, 2 (2002), 241-256.

[32] Raymond C Jones. 2008. The" why" of class participation: A question worth asking. College Teaching 56, 1 (2008), 59-63.

[33] Insung Jung, Seonghee Choi, Cheolil Lim, and Junghoon Leem. 2002. Effects of different types of interaction on learning achievement, satisfaction and 
participation in web-based instruction. Innovations in Education and Teaching International 39, 2 (2002), 153-162.

[34] Ellen Junn. 1994. " Pearls of wisdom": Enhancing student class participation with an innovative exercise. Fournal of Instructional Psychology 21, 4 (1994), 385-387.

[35] Chi-wen Kao and Bruce Gansneder. 1995. An assessment of class participation by international graduate students. Fournal of College Student Development 36, 2 (1995), 132-140.

[36] David A Karp and William C Yoels. 1976. The college classroom: Some observations on the meanings of student participation. Sociology \& Social Research 60, 4 (1976), 421-439.

[37] Antonia Koslow and Anthony A Piña. 2015. Using transactional distance theory to inform online instructional design. Instructional Technology 63 (2015).

[38] George D Kuh and P Umbach. 2004. College and character: Insights from the national survey of student engagement. New Directions for Institutional Research 2004 (06 2004), 37 - 54.

[39] David W McMillan and David M Chavis. 1986. Sense of community: A definition and theory. Fournal of Community Psychology 14, 1 (1986), 6-23.

[40] Michael G Moore. 1989. Three types of interaction. American fournal of Distance Education 3 (01 1989), 1-7.

[41] Michael R Neer. 1987. The development of an instrument to measure classroom apprehension. Communication Education 36, 2 (1987), 154-166.

[42] Wendy Nielsen, Eric KH Chan, and Namsook Jahng. 2010. Collaborative learning in an online course: A comparison of communication patterns in small and whole group activities. Fournal of Distance Education 24 (01 2010), 39-58.

[43] Kevin O'Connor. 2013. Class participation: Promoting in-class student engagement. Education 133, 3 (2013), 340-344.

[44] Larisa A Olesova, J Richardson, Donald Weasenforth, and Christine Meloni. 2011 Using asynchronous instructional audio feedback in online environments: A mixed methods study. MERLOT fournal of Online Learning and Teaching 7, 1 (2011), 30-42.

[45] Gary M Olson and Judith S Olson. 2000. Distance matters. Human-Computer Interaction 15, 2-3 (2000), 139-178.

[46] John Orwat, Shveta Kumaria, Marcia Spira, Lynn Boyle, and Amanda Besinger 2018. Class participation as a pedagogical tool in social work education. Social Work Education 37, 3 (2018), 361-377.

[47] Rena M Palloff and Keith Pratt. 2007. Building online learning communities: Effective strategies for the virtual classroom. John Wiley \& Sons.

[48] Kirsi Pyhältö, Jenni Stubb, and Kirsti Lonka. 2009. Developing scholarly communities as learning environments for doctoral students. International Fournal for Academic Development 14, 3 (2009), 221-232.

[49] Andrew Quinn. 2010. An exploratory study of opinions on clickers and class participation from students of human behavior in the social environment. Fournal of Human Behavior in the Social Environment 20, 6 (2010), 721-731.

[50] Gillian M Sandstrom and Elizabeth W Dunn. 2014. Social interactions and wellbeing: The surprising power of weak ties. Personality and Social Psychology Bulletin 40, 7 (2014), 910-922.

[51] Abdolhossein Sarrafzadeh, Hamid Gholam Hosseini, Chao Fan, and Scott P Overmyer. 2003. Facial expression analysis for estimating learner's emotional state in intelligent tutoring systems. In Proceedings 3rd IEEE International Conference on Advanced Technologies. IEEE, 336-337.

[52] Shauna Schullo, Amy Hilbelink, Melissa Venable, and Ann E Barron. 2007. Selecting a virtual classroom system: Elluminate live vs. Macromedia breeze (adobe acrobat connect professional). MERLOT fournal of Online Learning and Teaching 3, 4 (2007), 331-345.

[53] Jo L Shackelford and Marge Maxwell. 2012. Sense of community in graduate online education: Contribution of learner to learner interaction. International Review of Research in Open and Distributed Learning 13, 4 (2012), 228-249.
[54] Jeffrey R Stowell and Jason M Nelson. 2007. Benefits of electronic audience response systems on student participation, learning, and emotion. Teaching of Psychology 34, 4 (2007), 253-258.

[55] Jenni Stubb, Kirsi Pyhältö, and Kirsti Lonka. 2011. Balancing between inspiration and exhaustion: PhD students' experienced socio-psychological well-being. Studies in Continuing Education 33, 1 (2011), 33-50.

[56] Bude Su, Curtis J Bonk, Richard J Magjuka, Xiaojing Liu, and Seung-hee Lee. 2005. The importance of interaction in web-based education: A program-level case study of online MBA courses. Journal of Interactive Online Learning 4, 1 (2005), 1-19.

[57] Pei-Chen Sun, Ray J Tsai, Glenn Finger, Yueh-Yang Chen, and Dowming Yeh. 2008. What drives a successful e-Learning? An empirical investigation of the critical factors influencing learner satisfaction. Computers \& education 50, 4 (2008), 1183-1202.

[58] Sibel Tatar. 2005. Why keep silent? The classroom participation experiences of non-native-English-speaking students. Language and Intercultural Communication 5, 3-4 (2005), 284-293.

[59] Annetta Kit Lam Tsang. 2011. In-Class Reflective Group Discussion as a Strategy for the Development of Students as Evolving Professionals. International fournal for the Scholarship of Teaching and Learning 5, 1 (2011), n1.

[60] Juhani E Tuovinen. 2000. Multimedia distance education interactions. Educational Media International 37, 1 (2000), 16-24.

[61] Pam Vesely, Lisa Bloom, and John Sherlock. 2007. Key elements of building online community: Comparing faculty and student perceptions. MERLOT Journal of Online Learning and Teaching 3, 3 (2007), 234-246.

[62] Charalambos Vrasidas. 2000. Constructivism versus objectivism: Implications for interaction, course design, and evaluation in distance education. International fournal of Educational Telecommunications 6, 4 (2000), 339-362.

[63] Lilly Schubert Walker and Paul H Wright. 1976. Self-disclosure in friendship. Perceptual and Motor Skills 42, 3 (1976), 735-742.

[64] Hao-Chuan Wang, Susan F Fussell, and Leslie D Setlock. 2009. Cultural difference and adaptation of communication styles in computer-mediated group brainstorming. In Proceedings of the SIGCHI Conference on Human Factors in Computing Systems. 669-678.

[65] Qiaosi Wang, Shan Jing, David Joyner, Lauren Wilcox, Hong Li, Thomas Plötz, and Betsy Disalvo. 2020. Sensing Affect to Empower Students: Learner Perspectives on Affect-Sensitive Technology in Large Educational Contexts. In Proceedings of the Seventh ACM Conference on Learning@ Scale.63-76.

[66] Yuping Wang. 2004. Supporting synchronous distance language learning with desktop videoconferencing. Language Learning \& Technology 8, 3 (2004), 90-121.

[67] Robert R Weaver and Jiang Qi. 2005. Classroom organization and participation: College students' perceptions. The fournal of Higher Education 76, 5 (2005), 570-601.

[68] Mary Anne Weegar and Dina Pacis. 2012. A Comparison of two theories of learning-behaviorism and constructivism as applied to face-to-face and online learning. In Proceedings E-leader Conference, Manila.

[69] Jacob Whitehill, Zewelanji Serpell, Yi-Ching Lin, Aysha Foster, and Javier R Movellan. 2014. The faces of engagement: Automatic recognition of student engagement from facial expressions. IEEE Transactions on Affective Computing 5 , 1 (2014), 86-98.

[70] Masanori Yamada. 2009. The role of social presence in learner-centered communicative language learning using synchronous computer-mediated communication: Experimental study. Computers \& Education 52, 4 (2009), 820833.

[71] Tekeisha Denise Zimmerman. 2012. Exploring learner to content interaction as a success factor in online courses. International Review of Research in Open and Distributed Learning 13, 4 (2012), 152-165. 